\title{
Cationic Interactions Regulate the Initiation and Termination of Zoospore Activity in the Water Mould Achlya heterosexualis
}

\author{
By DONOVAN D. THOMAS* AND DEBRA L. BUTLER \\ Department of Biological Sciences, University of Windsor, Windsor, Ontario, Canada N9B 3P4
}

(Received 3 October 1988; revised 22 February 1989; accepted 30 March 1989)

The zoosporic phase of the water mould Achlya heterosexualis, initiated when zoospores emerge from cysts, is strongly influenced by cations. The concentrations of $\mathrm{Ca}^{2+}$ and $\mathrm{K}^{+}$present in the medium can determine whether or not zoospores will be released from cysts, whether zoospore motion will be approximately linear or circular, rapid or slow, and when zoospore activity will be terminated by encystment. Ionic effects on zoospore motility are rapid and reversible over short time spans; within a 2 min period motility can be strongly suppressed by increasing the $\left[\mathrm{K}^{+}\right]$and then restored by increasing the $\left[\mathrm{Ca}^{2+}\right]$. Trifluoperazine, considered to be an anti-calmodulin drug, both inhibits zoospore release, and arrests zoospore motility.

\section{INTRODUCTION}

The genus Achlya is characterized by immediate encystment of the asexual spores after emergence from the sporangium (Johnson, 1956). Alternative developmental paths for these spores are germination, by means of a germ tube, or zoospore production. The zoosporic phase starts with excystment; the cyst functions as a single-spored sporangium, from which the secondary zoospore emerges. While excystment in Oomycetes has received little attention, the availability of synchronously produced cysts of Achlya heterosexualis (Thomas, 1989) facilitates examination of this process. The zoospore phase is normally terminated by encystment, with the resultant cyst considered to have the same developmental alternatives, germination or zoospore production, as the original cyst. In the genus Achlya polyplanetism is common; as many as five repetitions of zoospore emergence followed by encystment have been observed (Salvin, 1940). Environmental factors affecting zoospore release and motility in Oomycetes include temperature, mechanical disturbance, nutrition (Hickman \& Ho, 1966) and ions (Fischer \& Werner, 1958; Mitchell \& Yang, 1966; Svensson \& Unestam, 1975; Grant et al., 1986; Soderhall \& Cerenius, 1987). Grant et al. (1986), working with Phytophthora zoospores, reported that $\mathrm{Na}^{+}$ induced encystment, and $\mathrm{Ca}^{2+}$ counteracted the effect of the $\mathrm{Na}^{+}$. This ionic interaction was incorporated into a model in which $\mathrm{Na}^{+}$uptake is regulated by a $\mathrm{Ca}^{2+}$-gated channel for monovalent ions. In Achlya, $\mathrm{Ca}^{2+}$ is required for asexual sporulation (Griffin, 1966), amino acid transport and growth (Cameron \& LeJohn, 1972); $\mathrm{K}^{+}$, with a vacuolar concentration assumed to be of the order of $100 \mathrm{~mm}$ (Thiel et al., 1988), is probably the most abundant cation present (Money \& Brownlee, 1987). Our work examines cation interactions, particularly between $\mathrm{Ca}^{2+}$ and $\mathrm{K}^{+}$, which regulate the motile phase of the Achlya life cycle by controlling its initiation and termination. Calmodulin has been implicated in spore release from both sporangia (Suryanarayana \& Thomas, 1986) and cysts (Suryanarayana, 1985). The possible role of calmodulin in the initiation and termination of the zoospore phase was examined using the calmodulin-binding drug trifluoperazine.

\section{METHODS}

Cyst preparations. Cysts of Achlya heterosexualis, ATCC 52875, were prepared as described by Thomas (1989); such cysts tend to release zoospores rather than to germinate by means of a germ tube. For most experiments, cysts were induced in the presence of $5 \times 10^{-4} \mathrm{M}-\mathrm{CaCl}_{2}$; those induced in deionized water are termed DW cysts. Cysts 
were used on the day of release or stored at $5{ }^{\circ} \mathrm{C}$ for not more than $2 \mathrm{~d}$. In order to remove the spent induction medium and to control the pH, the suspension was centrifuged at 2250 r.p.m. for 4 min. Cysts were washed and resuspended in $10^{-3} \mathrm{M}$-MOPS [3-( $N$-morpholino) propanesulphonate] buffer, $\mathrm{pH}$ 6.6.

Zoospore emergence. Each treatment usually involved $2.4 \mathrm{ml}$ MOPS suspension of cysts in a $35 \times 10 \mathrm{~mm}$ Petri dish. The suspension was made up to a total volume of $3 \mathrm{ml}$ using MOPS buffer with or without additives, and maintained at room temperature without shaking. Cysts were scored by microscopic observations at a magnification of $100 \times$. Initial cyst numbers ranged from 3 to $4 \times 10^{4}$ spores $\mathrm{ml}^{-1}$. Cysts were counted after they had settled to the bottom of the Petri dish; only full cysts, which are readily distinguished from empty ones, were counted. The diameter of the microscope field, $1064 \mu \mathrm{m}$, was established using a calibrated ocular micrometer. Each count represents the mean of five randomly selected fields. Treatments were in duplicate and experiments were repeated at least once. In experiments examining the effects of trifluoperazine on zoospore emergence from MOPS-washed cysts, concentrations tested were $0,1 \cdot 25,2 \cdot 5,5$ and $10 \mu \mathrm{M}$. To test for reversibility of inhibition of emergence by trifluoperazine, following a $3 \mathrm{~h}$ treatment, the cysts were washed and resuspended in fresh MOPS, while parallel unwashed treatments served as controls.

Zoospore motion and encystment. Zoospores were obtained by allowing cysts, unwashed, or washed and resuspended in MOPS, to remain at room temperature for 1-2 h. Motility tests were conducted in $35 \times 10 \mathrm{~mm}$ Petri dishes, with sequential counts of zoospores at the depth of the suspension which showed maximal zoospore activity. The effects of trifluoperazine on zoospores were tested at the concentrations mentioned previously. In fields with high zoospore activity, counts were made on one or two quadrants of the field. Spore preparations stained with $0.01 \%$ Calcofluor White M2R (Haigler et al., 1980) were examined for cyst wall morphology using an Olympus BH fluorescent microscope with a BG12 barrier filter. Encystment was confirmed by testing the smooth, rounded cells for resistance to hydrolysis in $0.3 \mathrm{M}-\mathrm{NaOH}$, based on the method of Tokunaga \& Bartnicki-Garcia (1971). For video analysis a $3 \mathrm{ml}$ zoospore suspension obtained from DW cysts in a $35 \times 10 \mathrm{~mm}$ Petri dish was gently decanted into a fresh Petri dish in order to minimize the number of residual cysts, which tended to settle to the bottom of the dish. A pipette was used to reduce the volume to $2 \mathrm{ml}$. Motility was recorded using a $10 \times$ objective of a Kyowa Medilux 12 trinocular microscope, a Panasonic WV-1500 television camera and a Panasonic AG-6050 time-lapse video cassette recorder. Randomly selected zoospores were tracked using tracings from the monitor onto acetate transparencies. Distances on the monitor field were calibrated using a stage micrometer. Each zoospore was tracked for at least $1 \mathrm{~s}$, represented by 60 frames, and its positions plotted at 5- or 15-frame intervals. Zoospore speed is the mean obtained from five or more tracks.

\section{RESULTS}

\section{Zoospore emergence from cysts}

The concentrations of the salts required to obtain at least $90 \%$ inhibition of emergence were $10^{-6} \mathrm{M}-\mathrm{LaCl}_{3}, 10^{-3} \mathrm{M}-\mathrm{KCl}$, and $10^{-2} \mathrm{M}-\mathrm{NaCl}, \mathrm{MgCl}_{2}$ or $\mathrm{CaCl}_{2} . \mathrm{Ca}^{2+}$ at $10^{-3} \mathrm{M}$ counteracted the inhibitory effects of $\mathrm{K}^{+}$and $\mathrm{Na}^{+}$but not that of $\mathrm{La}^{3+}$ at the concentrations tested. $\mathrm{Mg}^{2+}$ resembled $\mathrm{Ca}^{2+}$ in its ability to counteract the inhibitory effects of $\mathrm{K}^{+}$on zoospore emergence. The interaction between $\mathrm{K}^{+}$and $\mathrm{Ca}^{2+}$, with the latter counteracting $\mathrm{K}^{+}$inhibition of zoospore emergence, is shown in Fig. 1. Complete inhibition of emergence by the anti-calmodulin drug trifluoperazine was obtained at $5 \mu \mathrm{M}$, a concentration much lower than the $50 \mu \mathrm{M}$ required in the earlier study by Suryanarayana (1985). Differences from the present study were the use of an Achlya ambisexualis isolate, and unwashed cysts in the original $\mathrm{CaCl}_{2}$ induction medium. As in the earlier study, the complete inhibition of zoospore release was partially reversed after removal of the trifluoperazine; after $3 \mathrm{~h}$ in trifluoperazine (at 10 and $5 \mu \mathrm{M}$ ) and a subsequent $6 \mathrm{~h}$ with or without a single wash in MOPS, the wash treatments contained $5.4 \pm 0.9$ (mean $\pm \mathrm{SD}$ ) and $4.9 \pm 0.9$ zoospores per field, and the unwashed treatments, no zoospores. Untreated controls had $6 \cdot 1 \pm 0 \cdot 4$ zoospores per field.

\section{Zoospore motility and encystment}

The effects on zoospore motility of a number of cations, all applied as chloride salts, were comparable to those described above for the zoospore emergence studies. Treatments which had inhibited emergence also inhibited zoospore motility, usually by inducing encystment. Concentrations of the salts yielding at least $90 \%$ encystment were $10^{-6} \mathrm{M}-\mathrm{LaCl}_{3}, 10^{-3} \mathrm{M}-\mathrm{KCl}$, and $10^{-2} \mathrm{M}-\mathrm{NaCl}$ or $\mathrm{CaCl}_{2}$. At $10^{-3} \mathrm{M}, \mathrm{CaCl}_{2}$ counteracted the encystment-inducing effects of $\mathrm{K}^{+}$but not that of $\mathrm{La}^{3+}$ at the concentrations tested. The duration of motility in zoospore preparations was enhanced if the cysts had been washed and resuspended in MOPS buffer. For 

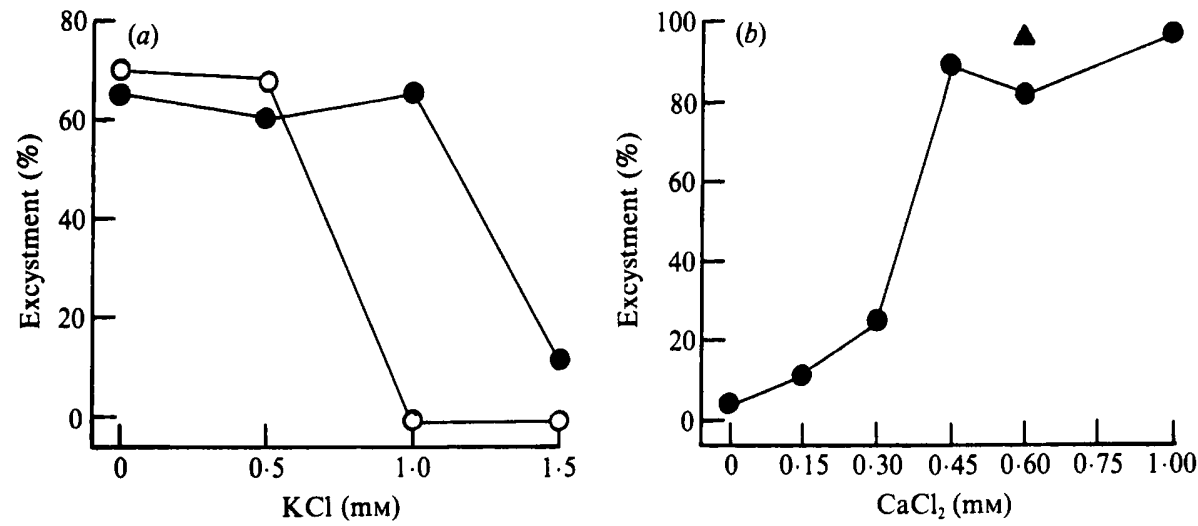

Fig. 1. Effects of $\mathrm{Ca}^{2+} / \mathrm{K}^{+}$interactions on zoospore emergence from cysts: $(a)$ effect of $[\mathrm{KCl}]$ on excystment in the absence $(O)$ and presence $(O)$ of $10^{-3} \mathrm{M}-\mathrm{CaCl}_{2} ;(b)$ effect of $\left[\mathrm{CaCl}_{2}\right]$ on excystment in the presence of $10^{-3} \mathrm{M}-\mathrm{KCl}$. $\Delta$, Effect of $6 \times 10^{-4} \mathrm{M}-\mathrm{CaCl}_{2}$ alone. Each point represents the mean of duplicates.

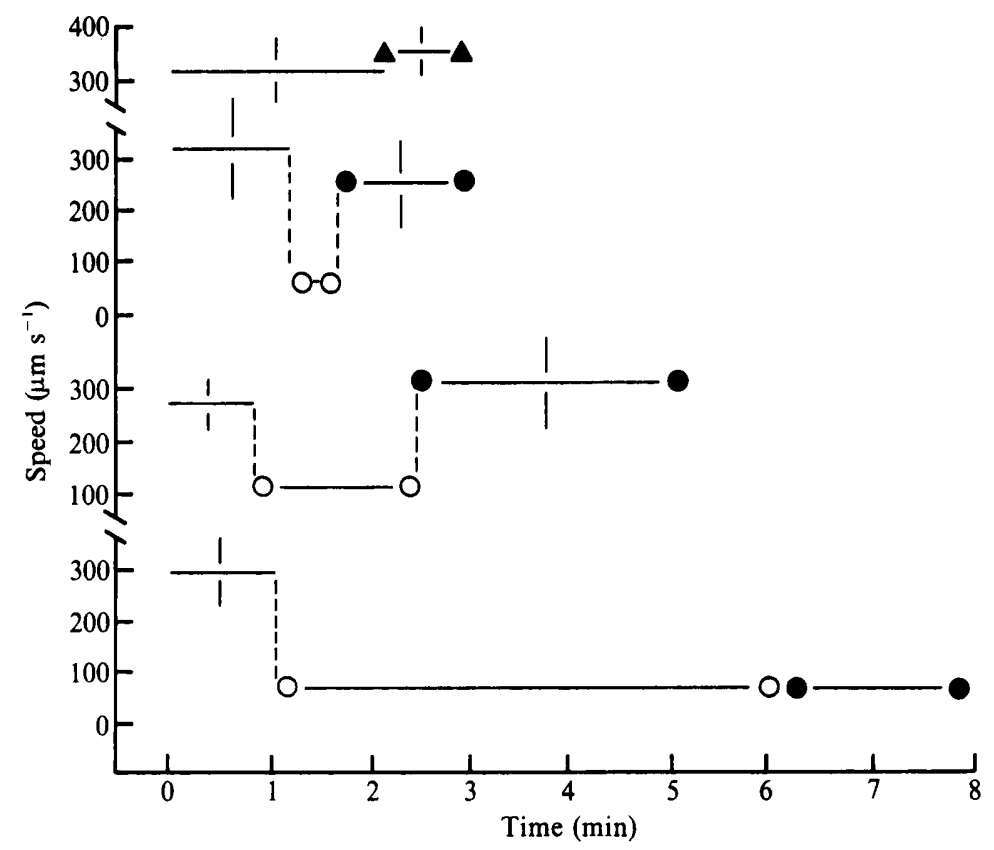

Fig. 2. Effects of $\mathrm{Ca}^{2+} / \mathrm{K}^{+}$interactions, both at $10^{-3} \mathrm{M}$, on zoospore motion. Initial speed (-), speed after adding $\mathrm{CaCl}_{2}$ alone $(\mathbf{\Delta})$, after adding $\mathrm{KCl}(\mathrm{O})$ and after adding $\mathrm{CaCl}_{2}$ subsequent to $\mathrm{KCl}(\mathrm{O})$. Each speed represents the mean of five measurements. The vertical bars, representing $2 \times$ the standard deviation of the means, are omitted when they fall within the marker symbols.

example, unwashed and MOPS-resuspended preparations after $21 \mathrm{~h}$ showed $27 \%$ and $81 \%$, respectively, of their initial motility. In the original sporulation induction medium containing $\mathrm{CaCl}_{2}$ at $5 \times 10^{-4} \mathrm{M}$, added $\mathrm{K}^{+}$at $10^{-3} \mathrm{M}$ extended the duration of zoospore motility. Without $\mathrm{K}^{+}$, zoospore activity was lost by $24 \mathrm{~h}$; with $\mathrm{K}^{+}$, zoospores remained active at $48 \mathrm{~h}$. When MOPS-washed cyst preparations were used, no sustaining effect of $\mathrm{K}^{+}$on zoospore motility in the presence of $\mathrm{Ca}^{2+}$ was observed. Analysis of video recordings revealed short-term responses of zoospores to $\mathrm{K}^{+}$and $\mathrm{Ca}^{2+}$. $\mathrm{K}^{+}$rapidly decreased zoospore speed; subsequent addition of $\mathrm{Ca}^{2+}$ within 2 min reversed the inhibition, but delayed application of $\mathrm{Ca}^{2+}$ was ineffective (Fig. 2). 

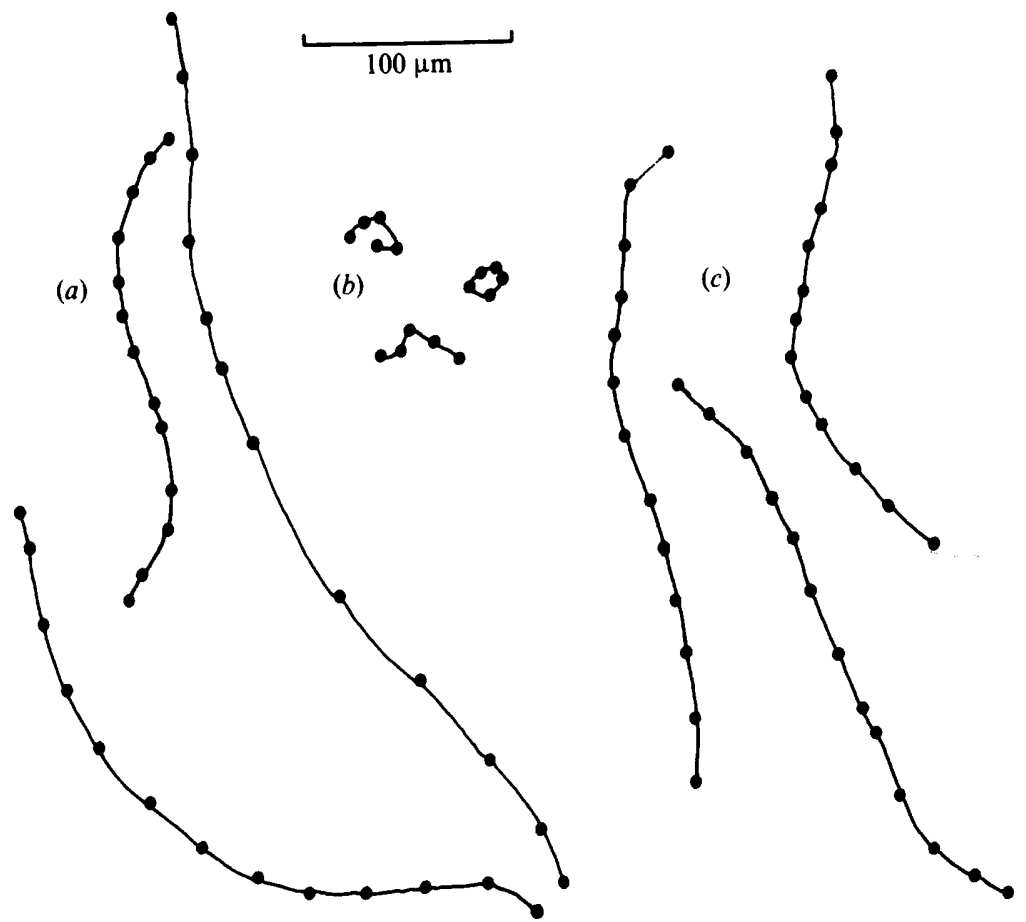

Fig. 3. Examples of zoospore tracks over a $1 \mathrm{~s}$ period: (a) initial, (b) after adding $\mathrm{KCl}$ to $10^{-3} \mathrm{M}$ and (c) after subsequent addition of $\mathrm{CaCl}_{2}$ to $10^{-3} \mathrm{M}$.

The tracks of the zoospores were strongly influenced by the ions (Fig. 3). Untreated zoospores maintained a constant course, their tracks approximately linear; $\mathbf{K}^{+}$-treated spores moved slowly with frequent changes in direction, typically moving in circles. The relationship between encystment-promoting treatments and germination was not examined in this study. Trifluoperazine at $5 \mu \mathrm{M}$ caused an almost immediate loss of motility in zoospores. Cell shape as observed using conventional light microscopy or Calcofluor fluorescence appeared irregular; however the cells appeared to be resistant to hydrolysis by $\mathrm{NaOH}$, suggesting that encystment had occurred.

\section{DISCUSSION}

Ionic conditions inhibiting emergence and those inhibiting zoospore motility (by promoting encystment) are similar, consistent with a common mechanism. If the fresh cyst can be considered to contain a zoospore primordium, then similarities between treatments that inhibit zoospore emergence and those that induce zoospore encystment may be expected on the grounds that both types of treatment may affect similar aspects of zoospore biology. One possibility is that ions which inhibit emergence may induce an encystment-like response of a zoospore initial within the cyst itself. Although the present results are restricted to the zoospore phase, and do not deal with the development of spores subsequent to encystment, we observed that $\mathrm{K}^{+-}$ induced cysts tend to produce germ tubes rather than zoospores.

Although $\mathrm{Ca}^{2+}$ was a relatively weak inhibitor of both zoospore emergence and zoospore mobility, the inhibitory effects of low concentrations of the anti-calmodulin agent, trifluoperazine, and of $\mathrm{La}^{3+}$ on emergence and on mobility, and the antagonism between $\mathrm{Ca}^{2+}$ and other ions during both processes are consistent with crucial (Thiel et al., 1988) roles of $\mathrm{Ca}^{2+}$ in the development of Achlya. Apparently distinct swimming modes, 'linear' promoted by $\mathrm{Ca}^{2+}$ and circular induced by $\mathrm{K}^{+}$, suggest effects of these ions on a zoospore steering mechanism. 
$\mathrm{Ca}^{2+}$ has been implicated in the regulation of flagellar and ciliary motility of several organisms (Schmidt \& Eckert, 1976). Interestingly, the circular swimming mode of secondary zoospores about to encyst resembles the motion described as characteristic of primary zoospores of Saprolegniales (Hickman \& Ho, 1966).

The interaction $\mathrm{Ca}^{2+}$ and $\mathrm{K}^{+}$in Achlya bears some resemblance to the $\mathrm{Ca}^{2+} / \mathrm{Na}^{+}$interaction in Phytophthora, which has been interpreted by Grant et al. (1986) in terms of a Ca ${ }^{2+}$-gated $\mathrm{Na}^{+}$ channel. While their work, consistent with that of Tsien et al. (1987), shows a strong $\mathrm{Ca}^{2+}$ response at $1 / 100$ th the $\mathrm{Na}^{+}$concentration, the interaction in Achlya occurs at approximately equal osmolarities. The critical events in the life of a zoospore emphasize the importance of osmotic regulation. Excystment, like spore release from sporangia (Money \& Webster, 1988) is inhibited by the non-permeant osmotic agent polyethylene glycol-4000 (D. L. Butler \& D. Laviolette, unpublished). Zoospore motility is terminated by swelling and encystment, in which osmoregulation plays a critical role (Grant et al., 1986).

The zoosporic phase is a vulnerable one, during which growth is suspended; while chemotaxis may increase proximity to a suitable substrate, prolonged motility will deplete energy reserves. Successful termination of this phase in nature would probably involve adhesion to, and encystment on a potential nutrient substrate (Nicholson, 1984). Bartnicki-Garcia \& Sing (1987) have demonstrated the critical importance of timing in determining whether encystment will occur with or without adhesion. Termination of the motile phase may be induced by ions diffusing from a potential host (Svensson \& Unestam, 1975) or substrate. The colonization of wounded fish by certain Oomycetes including Achlya sp. (Scott \& O'Bier, 1962) may be initiated by encystment induced by blood plasma ions, which can be present at concentrations exceeding $200 \mathrm{~mm}$ (Forster \& Berglund, 1953). Evidence for a distinction between chemotactic and encystment-inducing signals (Fischer \& Werner, 1958; Royle \& Hickman, 1964) suggests a means of decreasing premature encystment, and thus increasing success in substrate colonization.

A convenient method (Thomas, 1989) for raising synchronous populations of zoospores capable of sustained motility shows that oomycetous zoospore development although less studied (Soderhall \& Cerenius, 1987) is not inherently less tractable (Grant et al., 1984) than that of the chytrid Blastocladiella emersonii which has been the subject of intensive analysis (Soll \& Sonneborn, 1969; Lovett, 1975; Caldwell et al., 1986).

We are indebted to Drs Jan Ciborowski and Paul Taylor for advice and for the loan of video recording equipment, and to Diane Laviolette for consultations and technical assistance. This work was supported by the National Science and Engineering Research Council of Canada.

\section{REFERENCES}

Bartnicki-Garcia, S. \& Sing, V. O. (1987). Adhesion of zoospores of Phytophthora to solid surfaces. In Zoosporic Fungi in Teaching and Research, pp. 279283. Edited by M. S. Fuller \& A. Jaworski. Athens, Ga., USA: Southeastern Publishing Corporation.

Caldwell, J. H., van Brunt, J. \& Harold, F. M. (1986). Calcium-dependent anion channel in the water mold Blastocladiella emersonii. Journal of Membrane Biology 89, 85-97.

Cameron, L. E. \& LeJohn, H. B. (1972). On the involvement of calcium in amino acid transport and growth of the fungus Achlya. Journal of Biological Chemistry 257, 4729-4739.

Fischer, F. G. \& WeRner, G. (1958). Die Chemotaxis der Schwarmsporen von Wasserpilzen (Saprolegniaceen). Zeitschrift für physiologische Chemie 310, 6591.

Forster, R. P. \& BERglund, F. (1953). Total electrolyte distribution in blood and urine of the aglomerular teleost, Lophius piscatorius. Anatomical Record 117, 591-592.

Grant, B. R., Griffith, J. M., Irving, H. R. \& RADDA, M. (1984). An improved method for the synchronous production of zoospores from $P h y$ tophthora palmivora. Experimental Mycology 8, 382385.

Grant, B. R., Griffith, J. M. \& IRving, H. R. (1986). A model to explain ion-induced differentiation in zoospores of Phytophthora palmivora. Experimental Mycology 10, 89-98.

GrIFFIN, D. H. (1966). Effect of electrolytes on differentiation in Achlya sp. Plant Physiology 41, 1254-1256.

Haigler, C. H., Brown, R. M. \& Banziman, M. (1980). Calcofluor White ST alters the in vivo assembly of cellulose microfibrils. Science 210, 903905.

Hickman, C. J. \& Ho, H. H. (1966). Behaviour of 
zoospores in plant pathogenic Phycomycetes. Annual Review of Phytopathology 60, 1128-1135.

Johnson, T. W. (1956). The Genus Achlya: Morphology and Taxonomy. Ann Arbor, USA: University of Michigan Press.

LOVETT, J. S. (1975). Growth and differentiation of the water mold Blastocladiella emersonii: cytodifferentiation and the role of ribonucleic acid and protein synthesis. Bacteriological Reviews 39, 345-404.

Mitchell, J. E. \& YANG, C. Y. (1966). Factors affecting growth and development of Aphanomyces euteiches. Phytopathology 56, 917-922.

MONEY, N. P. \& BROWNLEE, C. (1987). Structural and physiological changes during sporangial development in Achlya intricata Beneke. Protoplasma 136, 199-204.

Money, N. P. \& Webster, J. (1988). Cell wall permeability and its relationship to spore release in Achlya intricata. Experimental Mycology 12, 169-179.

Nicholson, R. L. (1984). Adhesion of fungi to the plant cuticle. In Infection Processes of Fungi, pp. 7489. Edited by D. W. Roberts \& J. R. Aist. New York: Rockefeller Foundation.

RoYle, D. J. \& Hickman, C. J. (1964). Analysis of factors governing in vitro accumulation of zoospores of Pythium aphanidermatum on roots. II. Substances causing response. Canadian Journal of Microbiology 10, 201-219.

Salvin, S. B. (1940). The occurrence of five successive swarming stages in a non-sexual Achlya. Mycologia 32, 148-154.

SCHMIDT, J. A. \& ECKERT, R. (1976). Calcium couples flagellar reversal to photostimulation in Chlamydomonas reinhardtii. Nature, London 262, 713-715.

ScotT, W. W. \& O'BIER, A. H. (1962). Aquatic fungi associated with diseased fish and fish eggs. Progressive Fish Culture 24, 3-15.

Soderhall, K. \& Cerenius, L. (1987). Controlled growth and development in filamentous Oomycetes with emphasis on Aphanomyces spp. In Zoosporic Fungi in Teaching and Research, pp. 264-267. Edited by M. S. Fuller \& A. Jaworski. Athens, Ga., USA: Southeastern Publishing Corporation.

Soll, D. R. \& SonNeboRn, D. R. (1969). Zoospore germination in the water mold, Blastocladiella emersonii. II. Influence of cellular and environmental variables on germination. Developmental Biology 20, 218-235.

Suryanarayana, K. (1985). Studies on a calciumdependent activator protein, structurally and functionally homologous to calmodulin, from the water mold Achly a ambisexualis Raper. $\mathrm{PhD}$ thesis, University of Windsor, Canada.

Suryanarayana, K. \& Thomas, D. D. (1986). Asexual spore release from saprolegniaceous water moulds: involvement of calmodulin. Journal of General Microbiology 132, 593-598.

Svensson, E. \& UnestaM, T. (1975). Differential induction of zoospore encystment and germination in Aphanomyces astaci, Oomycetes. Physiologia plantarum 35, 210-216.

ThIEl, R., Schreurs, W. J. A. \& Harold, F. M. (1088). Transcellular ion currents during sporangium development in the water mould Achlya bisexualis. Journal of General Microbiology 134, 1089-1097.

Thomas, D. D. (1989). A method for preparing Achlya cysts with high zoosporogenic potential. Mycological Research 92, 233-235.

Tokunaga, J. \& BARTNICKI-GarCIA, S. (1971). Cyst wall formation and endogenous carbohydrate utilization during synchronous encystment of Phytophthora palmivora zoospores. Archiv für Mikrobiologie 79, 283-292.

Tsien, R. W., Hess, P., MCCleskey, E. W. \& ROSENBERG, R. L. (1987). Calcium channels: mechanisms of selectivity, permeation and block. Annual Review of Biophysics and Biophysical Chemis. try 16, 265-290. 